\title{
Insecticide-induced hormesis in an insecticide-resistant strain of the maize weevil, Sitophilus zeamais
}

\author{
N. M. P. Guedes, J. Tolledo, A. S. Corrêa \& R. N. C. Guedes \\ Departamento de Biologia Animal, Universidade Federal de Viçosa, Viçosa, Brazil
}

\section{Keywords \\ biphasic dose-response, fertility table, fitness, hormoligosis, pest resurgence \\ Correspondence \\ Raul Narciso C. Guedes (corresponding author), Departamento de Biologia Animal, Universidade Federal de Viçosa, Viçosa, MG 36571-000, Brazil. \\ E-mail: guedes@ufv.br}

Received: May 15, 2009; accepted: September 20, 2009

doi: 10.1111/j.1439-0418.2009.01462.x

\begin{abstract}
Sublethal responses to insecticides are frequently neglected in studies of insecticide resistance, although stimulatory effects associated with low doses of compounds toxic at higher doses, such as insecticides, have been recognized as a general toxicological phenomenon. Evidence for this biphasic dose-response relationship, or hormesis, was recognized as one of the potential causes underlying pest resurgence and secondary pest outbreaks. Hormesis has also potentially important implications for managing insecticide-resistant populations of insect-pest species, but evidence of its occurrence in such context is lacking and fitness parameters are seldom considered in these studies. Here, we reported the stimulatory effect of sublethal doses of the pyrethroid insecticide deltamethrin sprayed on maize grains infested with a pyrethroid-resistant strain of the maize weevil (Sitophilus zeamais) (Coleoptera: Curculionidae). The parameters estimated from the fertility tables of resistant insects exposed to deltamethrin indicated a peak in the net reproductive rate at $0.05 \mathrm{ppm}$ consequently leading to a peak in the intrinsic rate of population growth at this dose. The phenomenon is consistent with insecticideinduced hormesis and its potential management implications are discussed.
\end{abstract}

\section{Introduction}

Pesticide resistance is important not only as a model of adaptive microevolution, but also as a strategy of in situ biological monitoring of pesticide pollution (because of its association with high pesticide use) and as a financial and health concern in arthropod pests because it compromises their control (Brattsten et al. 1986; Knight and Norton 1989; Hopkin 1994; Hemingway et al. 2002). This phenomenon is the continuous subject of considerable attention, which historically has relied heavily on acute lethal effects of insecticides. Although the importance of such effects is undeniable, lethal acute estimates necessarily require the use of relatively high insecticide doses in the bioassays limiting the understanding of the potential impact of low (sublethal) doses of these compounds.

The reliance on high doses of toxic compounds for toxicity and environmental impact assessments has come under intense debate during the last decade (Calabrese and Baldwin 2001, 2003). Stimulatory effects associated with low doses of compounds that are toxic at higher doses, such as pesticides, have been widely reported lately and it is currently becoming recognized as a general toxicological phenomenon (Luckey 1968; Calabrese and Baldwin 2003; Calabrese 2004, 2008). Evidence of such biphasic dose-response relationship for pesticides is scant among insects and mites, but recognized as one of the potential causes underlying pest resurgence and secondary pest outbreaks (Hardin et al. 1995; Morse 1998; Zanuncio et al. 2003; Cohen 2006; Cutler et al. 2009; Guedes et al. 2009). In addition, fitness parameters and their implications have been understudied, despite their importance for a comprehensive understanding of the effects of pesticides in pest populations (Forbes and Calow 1999; Stark and Banks 2003; Guedes et al. 2009). Furthermore, insecticide-resistant populations of pest 
species have yet to be the target of attention regarding the possible occurrence of insecticide-induced hormesis and its implications.

Fertility tables were used here to test the potential occurrence of insecticide-induced stimulatory fitness response (i.e. insecticide-induced hormesis) in an insecticide-resistant strain of an important insect-pest species of stored cereal grains - the maize weevil [Sitophilus zeamais Motschulsky (Coleoptera: Curculionidae)]. We also tested the prediction by Forbes (2000) that the overall fitness of an organism is unlikely to be enhanced by the hormetic effect because life-history traits are not likely to simultaneously exhibit hormesis because of the energetic trade-offs among them.

\section{Material and Methods}

\section{Insects and insecticide}

A highly pyrethroid-resistant strain of $S$. zeamais was used in the present investigation $(>100 \times$, as periodically checked) (Guedes et al. 1994; Ribeiro et al. 2003; Araújo et al. 2008). This resistant strain was derived from insects collected in Jacarezinho County (state of Paraná, Brazil) in the late 1980s (Guedes et al. 1994, 1995), and maintained in large numbers (to minimize effects of genetic drift) and without insecticide selection since then. It has always been maintained in whole maize grains free of insecticides under controlled temperature $\left(25 \pm 2^{\circ} \mathrm{C}\right)$, relative humidity $(70 \pm 5 \%)$ and photoperiod (LD 12 : $12 \mathrm{~h}$ ). These were also the environmental conditions of the life table experiments. This strain is resistant to pyrethroids, but does not exhibit fitness cost (reduced reproductive output) associated with insecticide resistance (Guedes et al. 2006; Oliveira et al. 2007). The major pyrethroid resistance mechanism present is altered target-site sensitivity (mutation T929I in the sodium channel, following the housefly numbering; R. A. Araújo, personal communication) with secondary involvement of enhanced activity of glutathione $S$-transferases (Guedes et al. 1995; Fragoso et al. 2003, 2007).

The commercial formulation of the pyrethroid insecticide deltamethrin recommended for controlling the maize weevil $\left(\mathrm{K}\right.$-Obiol ${ }^{\circledR} 25 \mathrm{CE}$; Bayer CropScience Brasil, São Paulo, Brazil) was sprayed in batches of $1 \mathrm{~kg}$ of maize using manual sprayers with their nozzles directed down towards the grains at $20 \mathrm{~cm}$ high. A volume of $1 \mathrm{ml}$ was used to spray each grain batch at 3 bar pressure. Different grain batches were used for each replicate of the experi- ment and the sprayed grains were manually shaken to ensure even coverage over the kernels (every grain received insecticide, but not evenly because of their position over the surface). The sprayed grains were left to dry overnight before use and the sprayed doses of deltamethrin ranged from 0 to $5 \mathrm{ppm}$. The deltamethrin doses used were within the sublethal range for the insect strain, as determined in preliminary tests (lowest observable adverse effect concentration was $0.25 \mathrm{ppm}$ ), and no reproducing females were obtained at $10.00 \mathrm{ppm}$.

\section{Life table experiments and estimated parameters}

Fitness parameters were estimated for each insect cohort exposed to each dose of deltamethrin, in addition to a control (water only). Adult females from the stock strain were left to lay eggs in the grain batches sprayed; at least 60 eggs were used to establish each insect cohort (parental insects, P). The presence of eggs within each grain was recognized by the presence of egg plugs on the maize kernel and only grains with low egg density (one or two eggs per grain) were used to minimize the effect of mortality by larval competition within the grain. The experiment was replicated three times (i.e. three independent insect cohorts were used for each insecticide dose generating three life tables for each dose).

Upon adult emergence, the individual parental females [24-48 h old; sexed using rostrum patterns of shape and texture (Tolpo and Morrison 1965)] were transferred to individual jars containing a (parental) male from the same cohort and 40 grains sprayed with the suitable insecticide dose. The infested grains were replaced every 10 days with newly sprayed ones until (parental) female death. These replicated grain batches were independently sprayed following the same procedure as previously described. The replaced grains were kept until progeny (Fl) emergence after recording (every 10 days) the number of eggs laid per each parental female. Cohorts of 10 individualized parental females each were followed for each insecticide dose. The parental females were daily observed throughout their lives recording their survival, fecundity (eggs laid) and fertility (emerged female offspring, F1) until eventual death.

The experiment was carried out following a randomized blocks design (each block corresponding to an insect cohort per insecticide dose) and the fertility table parameters were calculated using the approximate method described by Maia et al. (2000) 
and following Southwood (1978). The parameters calculated with the fertility tables were the parental female survival at each age interval (\%), net reproductive rate (female offspring production per parental female, Ro), generation time (days, G) and intrinsic rate of population growth (daily female offspring production per parental female, $r_{m}$ ) (Southwood 1978; Maia et al. 2000). The predicted insect population after 90 days of storage under deltamethrin exposure was also estimated using the estimated rate of population growth and considering an exponential population growth. The body mass of the parental insects and their female progeny was also individually recorded to use female size as an additional measure of female quality (Smith and Lessells 1985; Smith 1991).

\section{Statistical analysis}

The parental female survival data were subjected to survival analysis and log-rank Chi-square to test the equality of the survival curves among doses of deltamethrin (PROC LIFETEST; SAS Institute 2002). The estimated mean survival time (days), net reproductive rate (Ro), generation time $(G)$ and intrinsic rate of population growth $\left(\mathrm{r}_{\mathrm{m}}\right)$ estimated for the parental females, the estimated population size after 90 days of storage under deltamethrin exposure and the body mass of female offspring (mg) were subjected to regression analysis using dose of deltamethrin as independent variable (TableCurve 2D; SPSS 2000). The regression models were tested from the simplest (linear and quadratic) to the alternative models of increasing complexity (non-linear peak models), and the model selection was based on simplicity, high F-values (and mean squares) and steep increase of adjusted- $\mathrm{R}^{2} \quad\left(\right.$ adj. $\left.-\mathrm{R}^{2}\right)$ with model complexity. Normality and residual distribution were also checked for each analysis to ascertain of parametric assumptions (TableCurve 2D; SPSS 2000). Correlation analysis between the intrinsic rate of population growth $\left(\mathrm{r}_{\mathrm{m}}\right)$ and mean survival time, net reproductive rate (Ro) and generation time $(G)$ were also carried out (PROC CORR; SAS 2002).

\section{Results}

\section{Parental female survival}

There were significant differences in daily survival of insecticide-resistant (parental) females (log-rank $\chi^{2}=29.76$, d.f. $\left.=6, \mathrm{P}<0.0001\right)$. The mean survival time of the insecticide-resistant females declined with insecticide dose from $108.67 \pm 6.03$ days to $69.00 \pm 2.01$ days (fig. 1).

\section{Female body mass}

There was no significant effect of deltamethrin exposure on the body mass of the parental females $\left(2.90 \pm 0.04 \mathrm{mg} ; \mathrm{F}_{1,178}=2.30 ; \mathrm{P}=0.13\right)$, nor on the body mass of the parental males $(2.82 \pm 0.04 \mathrm{mg}$; $\left.\mathrm{F}_{1,178}=0.67 ; \mathrm{P}=0.41\right)$. However, there were significant differences in body mass of female offspring exposed to increasing doses of deltamethrin $(\mathrm{P}=0.003)$. The body mass of the resistant female offspring declined at deltamethrin doses above $0.50 \mathrm{ppm}$ (fig. 2). Therefore, the quality of the female offspring produced was affected only by high doses of deltamethrin applied to the resistant strain.

\section{Fitness (demographic) parameters of parental insects}

Deltamethrin did not significantly affect the generation time for the insecticide-resistant strain of maize weevil $\left(74.38 \pm 1.74\right.$ days; $\left.\mathrm{F}_{1,16}=1.45 ; \mathrm{P}=0.25\right)$. In contrast, its respective net reproductive rates were significantly affected by exposure to sub-lethal doses of deltamethrin $(\mathrm{P}=0.0003)$. The net reproductive rates of the insecticide-resistant strain ranged from $103.15 \pm 17.62$ to $1.43 \pm 0.76$ female offspring produced per parental female (at 0.05 and $5.00 \mathrm{ppm}$ deltamethrin, respectively) and exhibited a peak at 0.05 ppm deltamethrin (fig. 3a).

The intrinsic population growth rate $\left(\mathrm{r}_{\mathrm{m}}\right)$ was significantly correlated with the net reproductive

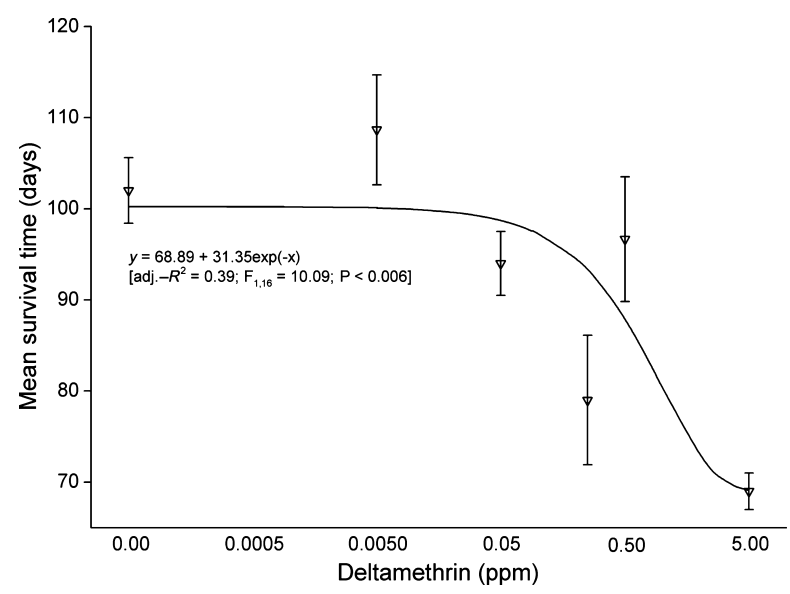

Fig. 1 Mean survival time ( \pm SEM) of females from an insecticide-resistant strain of maize weevil (Sitophilus zeamais) exposed to sublethal doses of deltamethrin $(n=3)$. 


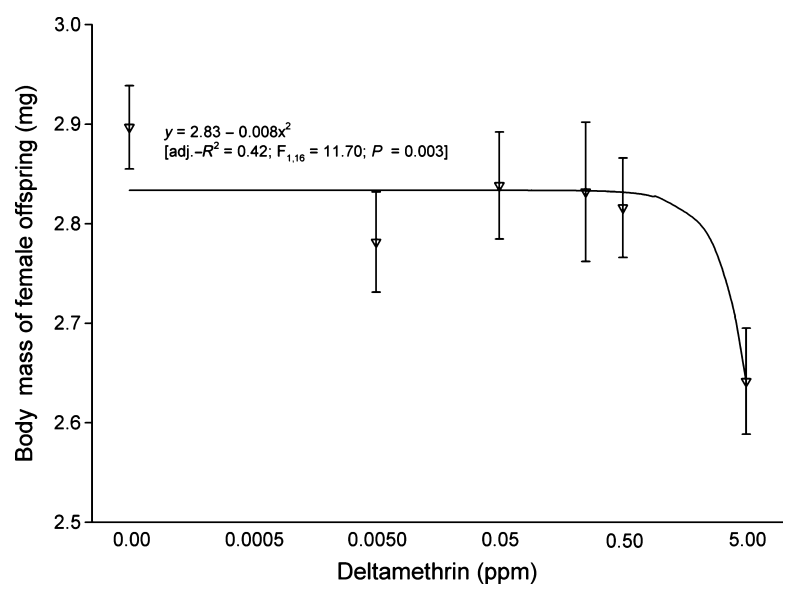

Fig. 2 Body mass ( \pm SEM) of female offspring (F1) from an insecticideresistant strain of maize weevil (Sitophilus zeamais) exposed to sublethal doses of deltamethrin $(n=3)$.

rate $(\mathrm{n}=18, \mathrm{r}=0.87, \mathrm{P}<0.0001)$ and showed similar trend to this parameter (fig. 3b), without significant contribution of generation time to such variation $(\mathrm{n}=18, \mathrm{r}=0.17, \mathrm{P}=0.51)$. The rate of population growth of the insecticide-resistant strain exhibited a peak at $0.05 \mathrm{ppm}$ deltamethrin. The predicted population size after 90 days of storage considering constant the exposure to deltamethrin (i.e. without significant insecticide degradation) also exhibited a peak at $0.05 \mathrm{ppm} 5.4 \times$ higher than the predicted population without insecticide exposure (fig. 4).

\section{Discussion}

Hormesis is characterized by a low-dose stimulation and a high-dose inhibition by a given compound (Calabrese and Baldwin 2003; Calabrese 2008). Two experimental conditions are necessary to recognize hormesis - a range of sublethal doses of a toxic compound and assessment parameters able to display both stimulatory and inhibitory responses (Calabrese and Baldwin 2003). The inhibitory response of the maize weevil to high doses of deltamethrin is demonstrated in our study by the negative rate of population growth (and fertility) obtained with the insecticide-resistant strain used in our experiments. Such negative rates of population growth indicate a reduction of insect population with time. In addition, the high doses of deltamethrin also led to a reduction in longevity of parental females and body mass (a surrogate estimate of quality) of insecticideresistant female offspring. A stimulatory response of
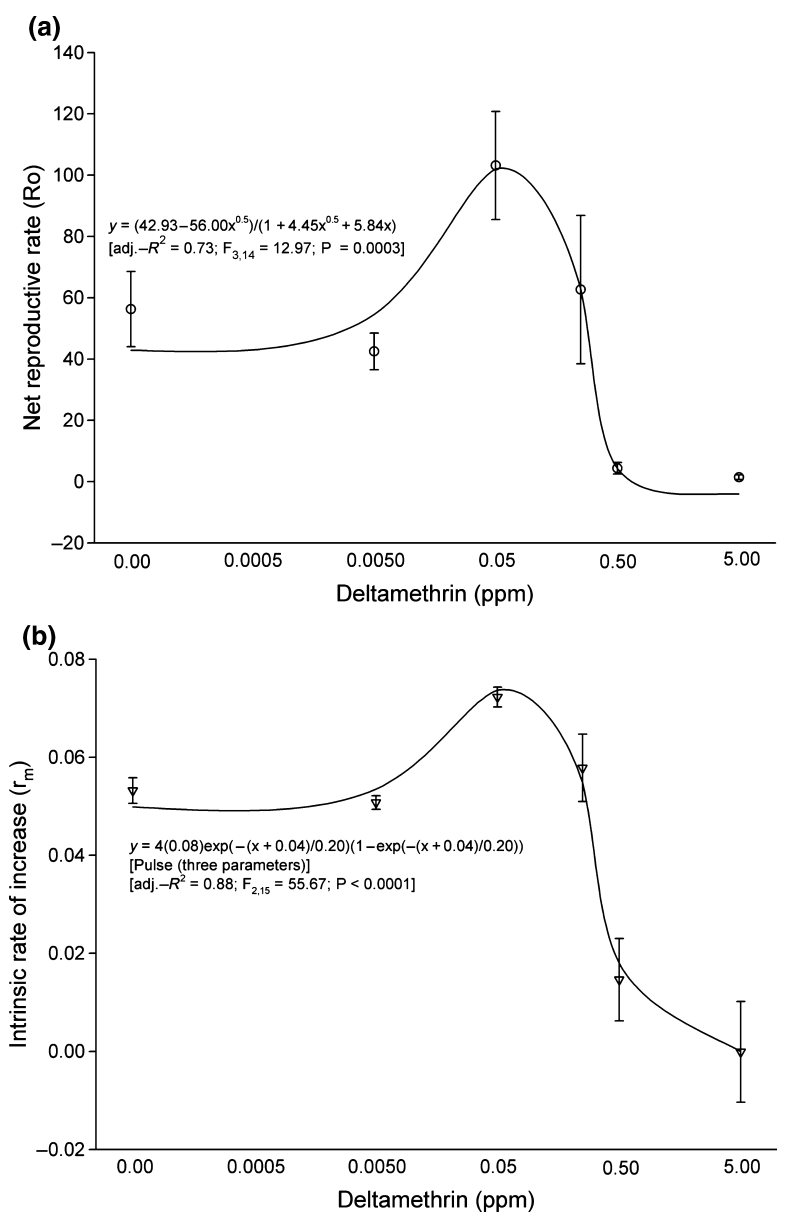

Fig. 3 Net reproductive rate $( \pm S E M)(a)$ and intrinsic rate of population growth $( \pm$ SEM) (b) of an insecticide-resistant strain of maize weevil (Sitophilus zeamais) exposed to sublethal doses of deltamethrin $(n=3)$.

the insecticide-resistant strain of maize weevil was also observed in our study by the peak in the rate of population growth (and fertility) observed at $0.05 \mathrm{ppm}$ deltamethrin, without compromise of female quality (indicated by lack of effect on body mass of the female offspring). Such conditions satisfy the hormesis criteria, which was evident at $0.05 \mathrm{ppm}$. Evidence of a hormesis-like stimulatory response (referred to as hormoligosis) of a diamondback moth strain [Plutella xylostella (Lepidoptera: Yponomeutidae)] selected for insecticide resistance was also reported in Japan (Sota et al. 1998), although with a confounding effect of insect mortality, which was prevented in our study.

Although providing evidence of insecticideinduced hormesis in an insecticide-resistant strain of maize weevil, we are unable to discern how general is the occurrence of hormesis in the maize weevil 


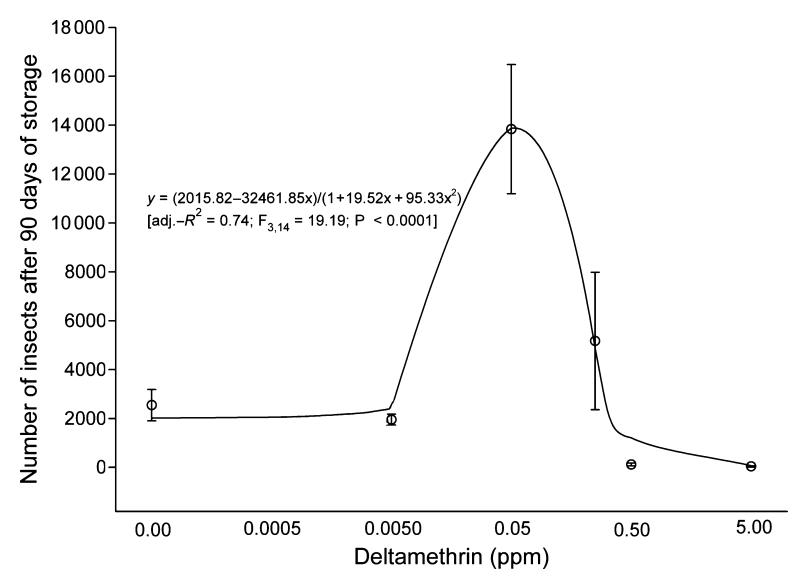

Fig. 4 Predicted population size ( \pm SEM) of an insecticide-resistant strain of maize weevil (Sitophilus zeamais) exposed to sublethal doses of deltamethrin $(n=3)$ during 90 days of storage.

since only a single strain was used in this study. The expansion of this investigation to different insecticide-resistant and insecticide-susceptible strains with differing genetic make-up will allow the recognition of the generality of such phenomenon, which was also earlier reported in the related species Sitophilus granarius by Kuenen (1958). This effort will also allow a better assessment of its potential impact in resistance management programs. However, simplified surrogate determinations of fitness will be necessary because the large number of fertility table studies required for such long-living insects (>5 months) makes the effort disheartening for this particular species (i.e. the maize weevil S. zeamais).

The detection of hormesis in the rate of population growth (and fertility) of insecticide-resistant insects reported here does not provide support for Forbes' prediction that the overall fitness of an organism is unlikely to be enhanced by hormesis because of their independent occurrence in lifehistory traits, which are constrained by energetic trade-offs among them (Forbes 2000). Although Forbes' prediction is consistent with the survey carried out at the time, such prediction was subjected to a single empirical test so far, which provided borderline results not allowing a definite conclusion (Guedes et al. 2009). It seems conceivable following the principle of resource allocation (Sibly and Calow 1986), that under lower doses of deltamethrin the exposed female diverts its energy resources to offspring production rather than to its maintenance, unlikely what would take place under exposure to higher doses of deltamethrin. However, the balance of such alternative paths of resource allocation has yet to be object of attention. Furthermore, we tested only a single insect strain under highly controlled conditions and additional testing of Forbes's predictions (Forbes 2000) is therefore necessary.

Hormesis may be a beneficial response when natural enemies of pest species are favoured by sublethal doses of an insecticide used for managing its host species, as recently reported for the predator Podisus distinctus (Heteroptera: Pentatomidae) (Guedes et al. 2009). In contrast, hormesis is a disadvantageous response when favouring the population increase of pest species potentially leading to pest resurgence and/or secondary pest outbreaks (Hardin et al. 1995; Morse 1998; Cutler et al. 2009), although such possibilities have yet to be empirically tested. Hormesis should also be recognized as a potential problem for managing pesticide-resistant populations of insect-pests since field doses of the insecticide will not control the resistant insects and may actually boost their population increase and frequency increase of the resistance alleles. They may also ultimately lead to problems of pest resurgence and/or secondary pest outbreaks depending on the system considered. As the label rate for deltamethrin control of the maize weevil is $0.5 \mathrm{ppm}$, the resistant insects are able to maintain population growth under this exposure and insecticide degradation will eventually boost its reproduction quickly increasing the frequency of resistant insects in the population. If deltamethrin exposure is considered constant during a 90-days storage period (i.e. without significant degradation), a $5.4 \times$ increase in population is expected under $0.05 \mathrm{ppm}$ deltamethrin compared with the expected population without insecticide exposure. Therefore, pesticide-induced hormesis is a potentially important phenomenon for the evolution of pesticide resistance and the design of resistance management programs, which has been neglected so far.

\section{Acknowledgements}

We thank the financial support of the Brazilian Sponsor Agency of Studies and Projects (FINEP) and the National Council of Scientific and Technological Development $(\mathrm{CNPq})$, in addition to the CAPES Foundation (Brazilian Ministry of Education) and the State Foundation of Research Aid (FAPEMIG). We also thank Dr J. P. Santos for providing the initial stock strain used in this study. Comments and suggestions provided by Prof. S. Vidal and two anonymous reviewers were greatly appreciated. 


\section{References}

Araújo RA, Guedes RNC, Oliveira MGA, Ferreira GH, 2008. Enhanced activity of carbohydrate- and lipid-metabilizing enzymes in insecticide-resistant populations of the maize weevil, Sitophilus zeamais. Bull. Entomol. Res. 98, 417-424.

Brattsten LB, Holyoke CW, Leeper JR, Raffa KF, 1986. Insecticide resistance: challenge to pest management and basic research. Science 231, 1255-1260.

Calabrese EJ, 2004. Hormesis: from marginalization to mainstream - a case for hormesis as the default dose-response model in risk assessment. Toxicol. Appl. Pharmacol. 197, 125-136.

Calabrese EJ, 2008. Hormesis: why it is important to toxicology and toxicologists. Environ. Toxicol. Chem. 27, 1451-1474.

Calabrese EJ, Baldwin LA, 2001. The frequency of $\mathrm{u}$-shaped dose responses in the toxicological literature. Toxicol. Sci. 62, 330-338.

Calabrese EJ, Baldwin LA, 2003. Hormesis: the doseresponse revolution. Annu. Rev. Pharmacol. Toxicol. 43, 175-197.

Cohen E, 2006. Pesticide-mediated homeostatic modulation in arthropods. Pestic. Biochem. Physiol. 85, 21-27.

Cutler GC, Ramanaidu K, Astatkie T, Isman MB, 2009. Green peach aphid, Myzus persicae (Hemiptera: Aphididae), reproduction during exposure to sublethal concentrations of imidacloprid and azadirachtin. Pest Manag. Sci. 65, 205-209.

Forbes VE, 2000. Is hormesis an evolutionary expectation? Funct. Ecol. 14, 12-24.

Forbes VE, Calow P, 1999. Is the per capita rate of increase a good measure of population-level effects in ecotoxicology? Environ. Toxicol. Chem. 18, 15441556.

Fragoso DB, Guedes RNC, Rezende ST, 2003. Glutathione-S-transferase detoxification as a potential pyrethroid resistance mechanism in the maize weevil, Sitophilus zeamais. Entomol. Exp. Appl. 109, 21-29.

Fragoso DB, Guedes RNC, Oliveira MGA, 2007. Partial characterization of glutathione s-transferases in pyrethroid-resistant and-susceptible populations of the maize weevil, Sitophilus zeamais. J. Stored Prod. Res. 43, 167-170.

Guedes RNC, Lima JOG, Santos JP, Cruz CD, 1994. Inheritance of deltamethrin resistance in a Brazilian strain of maize weevil (Sitophilus zeamais Motsch.). Int. J. Pest Manag. 40, 103-106.

Guedes RNC, Lima JOG, Santos JP, Cruz CD, 1995. Resistance to ddt and pyrethroids in Brazilian populations of Sitophilus zeamais Motsch. (Coleoptera: Curculionidae). J. Stored Prod. Res. 31, 145-150.

Guedes RNC, Oliveira EE, Guedes NMP, Ribeiro B, Serrão JE, 2006. Cost and mitigation of insecticide resistance in the maize weevil, Sitophilus zeamais. Physiol. Entomol. 31, 30-38.

Guedes RNC, Magalhaes LC, Cosme LV, 2009. Stimulatory sublethal response of a generalist predator to permethrin: hormesis, hormoligosis, or homeostatic regulation? J. Econ. Entomol. 102, 170-176.

Hardin MR, Benrey B, Coll M, Lamp WO, Roderick GK, Barbosa P, 1995. Arthropod pest resurgence: an overview of potential mechanisms. Crop Prot. 14, 3-18.

Hemingway J, Field L, Vontas J, 2002. An overview of insecticide resistance. Science 298, 96-97.

Hopkin SP, 1994. In situ biological monitoring of pollution in terrestrial and aquatic ecosystems. In: Handbook of ecotoxicology. Ed. by Calow P, Blackwell, Oxford, 397-427.

Knight AL, Norton GW, 1989. Economics of agricultural pesticide resistance in arthropods. Annu. Rev. Entomol. 34, 293-313.

Kuenen DJ, 1958. Influence of sublethal doses of DDT upon the multiplication rate of Sitophilus granarius (Coleopt. Curculionidae). Entomol. Exp. Appl. 1, 147-152.

Luckey TD, 1968. Insecticide hormoligosis. J. Econ. Entomol. 61, 7-12.

Maia AHN, Luiz AJB, Campanhola C, 2000. Statistical inference on associated fertility life table parameters using jacknife technique: computational aspects.

J. Econ. Entomol. 93, 511-518.

Morse JG, 1998. Agricultural implications of pesticideinduced hormesis of insects and mites. Hum. Exp.

Toxicol. 17, 266-269.

Oliveira EE, Guedes RNC, Tótola MR, Marco PD, 2007. Competition between insecticide-susceptible and resistant populations of the maize weevil, Sitophilus zeamais. Chemosphere 69, 17-24.

Ribeiro BM, Guedes RNC, Oliveira EE, Santos JP, 2003. Insecticide resistance and synergism in Brazilian populations of Sitophilus zeamais. J. Stored Prod. Res. 39, 21-31.

SAS, 2002. SAS/Stat, vol. 8. SAS Institute, Cary, NC, USA.

Sibly RM, Calow P, 1986. Physiological ecology of animals - an evolutionary approach. Blackwell, Oxford.

Smith RH, 1991. Genetic and phenotypic aspects of life-history evolution in animals. Adv. Ecol. Res. 21, 63-120.

Smith RH, Lessells CM, 1985. Oviposition, ovicide and larval competition in granivorous insects. In: Behavioural ecology: ecological consequences of adaptative behavior. Ed. by Sibly RM, Smith RH, Blackwell, London, 423-448.

Sota N, Motoyama N, Fujisaki K, Nakasuji F, 1998. Possible amplification of insecticide hormoligosis from resistance in the diamondback moth, Plutella xylostella (lepidoptera: Yponomeutidae). Appl. Entomol. Zool. 33, 435-440. 
Southwood TRE, 1978. Ecological methods with particular reference to the study of insect populations. 2nd edn. Chapman \& Hall, London.

SPSS, 2000. Tablecurve 2D: user's guide. SPSS, Chicago. Stark JD, Banks JE, 2003. Population-level effects of pesticides and other toxicants on arthropods. Annu. Rev. Entomol. 48, 505-519.
Tolpo NC, Morrison EO, 1965. Sex determination by snout characteristics of Sitophilus zeamais Motschulsky. Tex. J. Sci. 7, 122-124.

Zanuncio TV, Serrão JE, Zanuncio JC, Guedes RNC, 2003. Permethrin-induced hormesis on the predator Supputius cincticeps (stal, 1860) (Heteroptera: Pentatomidae). Crop Prot. 22, 941-947. 